\title{
Relação entre a Percepção do Clima Organizacional e o Comportamento Organizacional Positivo: Estudo no Setor de Obras da Prefeitura de Tamboara-PR ${ }^{1}$
}

\author{
Relationship Between the Perception of Organizational Climate \\ and Positive Organizational Behavior : Study on Construction \\ Sector in the City Hall of Tamboara-PR
}

\section{Relación entre la Percepción del Clima Organizacional y Comportamiento Organizacional Positivo: Estudio sobre Sector de la Construcción de la Ciudad de Tamboara-PR}

\author{
João Paulo dos Santos Sanches \\ Graduado em Administração pela Universidade Estadual do Paraná - Campus Paranavaí \\ Diretor de Divisão de Recursos Humanos da Prefeitura Municipal de Tamboara, PR \\ Praça Isabel Marcos Beltrame, 2000 - Centro, Tamboara - PR, (44) 3460-1170 \\ e-mail: jp221188@hotmail.com
}

\author{
André Luís de Castro \\ Professor Departamento de Administração da Universidade Estadual do Paraná - Campus Paranavaí \\ Doutorando em Administração Pública e Governo - Fundação Getúlio Vargas \\ Endereço: Av. Gabriel Esperidião, SN, Paranavaí, PR, (44) 3424-0100 \\ e-mail: ancastro@gmail.com
}

\section{RESUMO}

\begin{abstract}
A Administração Pública tem passado por uma série de reformas, uma delas é a transição do modelo burocrático para o gerencial, essa nova maneira de gestão tem como preceitos a qualidade nos serviços, a busca por eficiência e a redução de custos. Nesse contexto, a Gestão de Pessoas possui a responsabilidade de movimentar, desenvolver e valorizar os profissionais para a consecução dos objetivos organizacionais. Um dos aspectos que deve ser observado pelos gestores é a percepção que os funcionários têm sobre a organização, pois a partir dessa assimilação é que os mesmos avaliam e sentem-se satisfeitos ou não, podendo consequentemente gerar resultados indesejáveis para a organização, já que esta avaliação realizada pelos funcionários exerce influência em seu comportamento organizacional. Essa percepção, quando extraída do coletivo, também é conhecida como clima organizacional. O objetivo da pesquisa é analisar como a percepção sobre o clima organizacional dos servidores do setor de obras, da prefeitura de Tamboara-PR, influencia em seu comportamento organizacional positivo (COP). O trabalho é classificado como de tipo explicativo, sendo a coleta de dados realizada por meio de questionário e entrevistas com uma população de 24 funcionários. Os resultados demostraram que a percepção dos servidores sobre o clima organizacional possui relação com o seu comportamento organizacional positivo. Nesse âmbito, a importância dada pelos entrevistados ao fator de maior impacto negativo no clima
\end{abstract}

\footnotetext{
${ }^{1}$ Artigo recebido em 28.01.2015. Revisado pelos pares em 07.07.2015 (blind review). Ajustado e Aceito para publicação em 11.09.2015. Recomendado para publicação por José Ribamar Marques de Carvalho (Editor Científico). Publicado em 05.12.2015. Organização responsável UACC/CCJS/UFCG.
}

REUNIR: Revista de Administração, Contabilidade e Sustentabilidade ISSN: 2237-3667, Vol. 5, n. 3, p.19-38, 2015 
organizacional, a cooperação entre colegas, sugere a necessidade da empatia, capacidade psicológica promovida pelo COP.

Palavras-chave: Clima Organizacional. Comportamento Organizacional Positivo (COP). Gestão de Pessoas.

\begin{abstract}
The public administration has undergone a series of reforms, one of them is the transition the bureaucratic model for the managerial, this new way of management have as precepts quality in services, search by efficiency and the cost reduction. In this context the Personnel Management has the responsibility to move, develop and value the professional to the achievement of organizational goals. One of the aspects that must be observed by managers is the perception that employees have on the organization, because from this assimilation is that they evaluate and they feel satisfied or not, and may consequently generate undesirable outcomes for the organization, since this assessment performed by employees influence on her organizational behavior. This realization, when extracted from the collective, is also known as organizational climate. The research objective is: to analyze how the perception about of the organizational climate of employees of the sector of works, of the City of Tamboara PR, influences on their individual organizational behavior. The work is classified as an explanatory type, and data collection conducted through a questionnaire and interviews with a population of 24 employees. The results showed that the perception of the servers on the organizational climate has relationship with its positive organizational behavior. In this context, the importance given by respondents to the most negative impact factor in organizational climate, cooperation between colleagues, suggests the need for empathy, psychological capacity promoted by the COP.
\end{abstract}

Keywords: Organizational Climate. Positive Organizational Behavior. Human Resources.

\title{
RESUMEN
}

La administración pública ha sido objeto de una serie de reformas, uno de los cuales es la transición del modelo burocrático de gestión, esta nueva forma de gestión es preceptos servicios de calidad, la búsqueda de la eficiencia y reducción de costos. En este contexto, la gestión de las personas tiene la responsabilidad de avanzar, desarrollar y mejorar el profesional para el logro de los objetivos organizacionales. Un aspecto que debe tenerse en cuenta por los administradores es la percepción que los empleados tienen sobre la organización, ya que desde que la asimilación es que se evalúan y se sienten satisfechos o no, y por lo tanto puede dar lugar a resultados no deseados para la organización, ya que esto evaluación realizada por empleados influye en su comportamiento organizacional. Esta toma de conciencia, cuando se extrae del colectivo, también se conoce como el clima organizacional. El objetivo de la investigación es analizar cómo el sector, Tamboara-PR prefectura, su influencia positiva en el comportamiento organizacional de la percepción del clima organizacional de servidores funciona. El trabajo se clasifica como un tipo de motivos, y la recopilación de datos realizada a través de un cuestionario y entrevistas con una población de 24 empleados. Los resultados mostraron que la percepción de los servidores en el clima organizacional tiene relación con su comportamiento organizacional positivo. En este contexto, la importancia dada por los encuestados para el factor de impacto más negativo en el clima organizacional, la cooperación entre colegas, sugiere la necesidad de que la empatía, la capacidad psicológica promovida por la COP.

Palabras clave: Clima Organizacional. Comportamiento Organizacional Positivo. Recursos humanos.

\section{INTRODUÇÃO}

Boas práticas de gestão de pessoas tornaram-se indispensáveis para qualquer organização, independente de seu porte (micro, pequena, média ou grande) e segmento, seja ela privada ou pública. Apesar da substituição tecnológica do homem em algumas áreas, fato que vem ocorrendo cada vez com maior frequência, ainda é

\author{
REUNIR: Revista de Administração, Contabilidade e Sustentabilidade
}

ISSN: 2237-3667, Vol. 5, n. 3, p.19-38, 2015 
perceptível a dependência do fator humano nas organizações, uma vez que são essas pessoas que têm contato direto com clientes ou usuários e que realizam os serviços essenciais para a existência da organização. Considerando que cada pessoa leva para seu trabalho aspectos pessoais que a diferencia das demais, o papel do administrador torna-se mais complexo, tendo como desafio encontrar ações que sejam adequadas para lidar com essa diversidade de percepções.

A maneira como os indivíduos percebem o ambiente organizacional e como este reflete em seu comportamento é chamado de Clima Organizacional (KNAPIK, 2008). Um Clima Organizacional adequado pode contribuir com o Comportamento Organizacional Positivo (COP), definido por Newstron (2008) como um ambiente de trabalho que estimula o surgimento de capacidades psicológicas nos funcionários como a empatia e a resistência. A relação entre Clima Organizacional e COP também é destacada por Xavier (1986), segundo o qual é importante ter conhecimento do clima organizacional, pois ele revela elementos que influenciam de forma direta e concreta no comportamento organizacional dos indivíduos e das equipes. Oliveira e Junior (2013) acrescentam que proporcionar um clima organizacional favorável é uma forma de incentivar o comportamento positivo dos empregados.

A despeito da importância dessa discussão, poucos são os trabalhos que tratam sobre o tema. Dos vinte e nove artigos encontrados nos anais do ENANPAD (Encontro Nacional de Pós-Graduação e Pesquisa em Administração) sobre clima organizacional, poucos são aqueles que apresentam a relação entre o clima organizacional e comportamento ou desempenho. O artigo de Cunha et. al. (2013) destaca que nos últimos anos, os estudos sobre comportamento organizacional positivo, têm ganhado importância na literatura internacional.

Pensando em preencher essa lacuna, o trabalho visa à compreensão da relação entre clima organizacional e comportamento organizacional positivo. Esse entendimento pode resultar na melhoria da qualidade de vida para os trabalhadores e na ampliação de conhecimentos no campo de comportamento organizacional. $\mathrm{O}$ objeto empírico dessa pesquisa são servidores de uma instituição pública, o que destaca a importância da pesquisa, uma vez que o objetivo principal do setor público é proporcionar o bem comum, o que leva a uma necessidade de haver funcionários satisfeitos para que consequentemente esses realizem suas atribuições de forma competente em benefício de toda sociedade.

Considerando essa discussão, a pesquisa visa responder a seguinte questão: qual é a relação entre clima organizacional e o comportamento organizacional positivo na percepção dos funcionários do setor de obras da Prefeitura de TamboaraPR?

REUNIR: Revista de Administração, Contabilidade e Sustentabilidade ISSN: 2237-3667, Vol. 5, n. 3, p.19-38, 2015 
Este trabalho está estruturado da seguinte maneira: "Clima organizacional", , "Comportamento organizacional positivo" e "Relação entre clima organizacional e comportamento organizacional positivo" compõe o referencial teórico. Em seguida é exposta a metodologia utilizada na pesquisa, em seguida a apresentação e análise dos Resultados e por fim, as considerações finais sobre os resultados obtidos.

\section{REFERENCIAL TEÓRICO}

\subsection{Clima Organizacional}

A administração das organizações passou por uma mudança de foco, tarefas fracionadas e padronizadas foram substituídas por outras mais complexas, baseadas no comportamento dos indivíduos e que exigem maior capacidade intelectual (EBOLI, 2002). A partir desse cenário organizacional, tornou-se indispensável a presença de um administrador específico para gerir os recursos humanos.

Uma das variáveis que influenciam no comportamento do funcionário é a sua percepção sobre aspectos do ambiente de trabalho. Essa percepção quando extraída do coletivo, também é conhecida como clima organizacional. Conforme Andrade et. al. (2011), o termo clima teve como pioneiros em seu uso os psicólogos sociais Lewin, Lippitt e White em pesquisa publicada no ano de 1939. O estudo trazia conceitos sobre atmosfera social que também ficou conhecida como clima social, estudo esse que se referia a processos sociais, comportamentais e emocionais (sentimentais).

No Brasil, a pesquisa sobre clima organizacional foi introduzida e aplicada por Edela Lanzer Pereira de Souza em 1978, pesquisadora da Universidade Federal do Rio Grande do Sul que elaborou trabalhos em organizações públicas e privadas, utilizando como base o modelo criado por Litwin e Stringer em 1968 (BISPO, 2006).

Atualmente, o clima organizacional tem estado em evidência, como um conhecimento essencial para as organizações, uma vez que trata de aspectos que influenciam direta e indiretamente na eficácia organizacional.

Essa importância é destacada por Kolb et. al. (1978), os quais afirmam que as empresas podem ser mais eficazes por meio da administração do clima organizacional. Para isso, deve procurar satisfazer as necessidades dos funcionários, fazendo com que o comportamento gerado seja direcionado para a concretização dos objetivos da organização. Para Martins (2008), a importância do clima organizacional ocorre pela influência que, percebida pelo funcionário, afeta em sua qualidade de vida e consequentemente seu desempenho funcional. Nesse sentido, Payne e Mansfield (1973), destacam que o clima organizacional é um elo que liga as 
expectativas e interesses pessoais às necessidades, políticas e diretrizes organizacionais.

Knapik (2008) afirma que o clima organizacional pode ser definido como atmosfera psicológica existente em uma organização ou setor. Traduz-se pela forma como os indivíduos percebem o ambiente e de como isso reflete em seu comportamento. Ainda, de acordo com a autora o clima tem relação com a motivação dos grupos, e consequentemente, o resultado da visão dos funcionários sobre a empresa podem ser positivo e benéfico ou negativo e maléfico.

O estudo do clima organizacional é um instrumento que gera resultados objetivos com o intuito de revelar possíveis problemas na administração. Um bom clima organizacional gera benefícios para organização, funcionários e clientes, sendo que o oposto, isto é, um clima não favorável, pode gerar resultados ruins. Os ganhos do clima favorável relacionam-se a benefícios psicológicos e consequentemente monetários, pois a satisfação de funcionários e clientes reflete na satisfação do consumidor, além de o nível de rotatividade e absenteísmo ser baixo, gerando menos custos com recrutamento, seleção, treinamento e despesas com verbas rescisórias. Em contrapartida, um clima instável, gera descontentamento para empregados e empregadores, o que reflete negativamente na satisfação dos clientes, além dos custos com turnover (Rotatividade de pessoal) e absenteísmo. Por fim, um clima neutro, nem muito bom e nem muito ruim, é o meio termo, em que a principal característica é a indiferença e a apatia (BISPO, 2006).

A partir do tipo de clima que a organização se encontra, juntamente com outros fatores internos e externos, os funcionários reagirão com determinados comportamentos. O resultado desse reflexo no comportamento pode ser maximizado quando positivo ou minimizado quando negativo.

Os tipos de clima organizacional são influenciados por diferentes fatores que alteram o comportamento das pessoas nas organizações. Os fatores internos são apresentados por Bispo (2006): ambiente organizacional - determina o nível de relacionamento necessário entre os funcionários para que esses executem as tarefas individuais ou em grupo; assistência aos empregados - determina o grau de assistência que a empresa vai oferecer aos funcionários, como assistência médica e dentária; estrutura organizacional - mensura o nível de influência que a estrutura tem sobre os funcionários e suas atividades; incentivos laborais - tem por objetivo obter retorno por meio do reconhecimento do trabalho realizado pelos funcionários; nível sociocultural - busca verificar se o nível intelectual e cultural dos funcionários é compatível com as tarefas que os mesmos vão executar; remuneração - analisa se o salário está de acordo com o nível das atividades executadas; segurança laboral mensura o nível de estabilidade dos funcionários; vida profissional - procura 
reconhecer o quanto os funcionários se identificam com a empresa e o quanto se sentem satisfeitos em trabalhar nesta organização. Desses fatores, Tamayo (1999) destaca que a estrutura organizacional é a principal influenciadora no clima organizacional.

Santos et. al. (2009) reforçam esses fatores, destacando: a equidade salarial, que visa saber se há distorções, internamente e externamente, na remuneração paga aos empregados; instalações físicas, que verifica a satisfação dos funcionários com aspectos relacionados ao nível de segurança em situações de periculosidade e insalubridade laboral; e o relacionamento e cooperativismo entre os funcionários, que busca saber qual o nível de integração entre estes na execução das atividades organizacionais. Além disso, também há a influência do estilo gerencial, um fator que visa indicar o nível de satisfação que o empregado tem para com os seus superiores, avaliando a qualidade de direção por meio dos aspectos: relacionamento, competência, feedback, capacidade de coordenação entre outros. Sobre esse item, Oliveira e Junior (2013) afirma que relações saudáveis entre gestores e subordinados, que contribuem para um bom clima organizacional, são uma maneira de induzir o comportamento positivo dos funcionários, impactando em melhor desempenho das atividades.

Dessa maneira, o comportamento do funcionário pode sofrer influência desses fatores que podem prejudicar ou contribuir no chamado "comportamento organizacional positivo".

\subsection{Comportamento Organizacional Positivo}

O comportamento humano recebe diferentes influencias e pode impactar nos resultados organizacionais. Knapk (2008) destaca que existem duas variáveis que influenciam no comportamento dos indivíduos, as intrínsecas, como sua percepção, valores pessoais, motivação e personalidade, e as extrínsecas, como as políticas, diretrizes, método de execução de tarefas, gratificações e penalidades, além do nível de confiança que a empresa tem para com os empregados.

Devido a importância da influencia desses fatores no comportamento muitas pesquisas passaram a ser desenvolvidas com esse tema. De acordo com Chiuzi et. al. (2012), a partir do início dos estudos em psicologia positiva de Seligman e Csikszentmialyi no ano de 2000, outros pesquisadores passaram a utilizar em seus trabalhos perspectivas positivas, com temas que abrangem análises sobre o bem-estar organizacional e também o comportamento organizacional positivo (COP).

Esse termo é definido como a aplicação de forças norteadas positivamente para os indivíduos e suas capacidades psicológicas, podendo essa ação ser 
mensurada, gerenciada e desenvolvida de maneira que melhore o desempenho desses trabalhadores. O COP não possui relação somente com a ideia de crescimento pessoal, como aquelas que permeiam os best-sellers por (LUTHANS, 2002).

Nesse sentido, Seligman e Csikszentmihalyi (2000) afirmam que a psicologia positiva não se baseia no auto-engano, na fé, ou em modas. Buscando ir além do senso comum, muitas pesquisas buscam definições para o COP. Newstrom (2008, p. 452) o define como a busca de "[...] uma cultura do local do trabalho que estimule o surgimento de sentimentos de otimismo, empatia, apreço, coragem e resistência". A definição de Palma et. al. (2007) diz que o COP busca unir o desenvolvimento de recursos humanos à gestão do desempenho nas organizações. Esses conceitos demonstram que o COP procura estudar aspectos positivos nos indivíduos, como destacados por Seligman e Csikszentmihalyi (2000), em que a psicologia não visa apenas estudar os pontos negativos como doenças, fraquezas e consequências danosas, ela é também a ciência que estuda as virtudes e os pontos fortes. Esse aspecto do COP também é destacado por Siqueira (2014) e McShane e Glinow (2014).

A percepção que os indivíduos têm sobre a organização pode ter influência no comportamento organizacional. Nesse sentido, entender a relação entre clima organizacional e comportamento organizacional positivo pode contribuir para a gestão de uma organização.

\section{Relação entre Clima Organizacional e Comportamento Organizacional Positivo}

A relação entre o clima organizacional e o comportamento organizacional positivo pode ser a chave para aprimorar as práticas de gestão e o desempenho dos profissionais. Contudo, Espindola e Oliveira (2009) afirmam que determinar uma relação concreta e aceitável entre clima e comportamento organizacional não é simples, mas nota-se que as duas variáveis estão ligadas aos empregados e às influências advindas do ambiente organizacional.

No entanto, alguns pesquisadores demonstram essa relação. Xavier (1986) afirma que o conhecimento do clima organizacional é importante para as organizações por revelar os elementos que influem de forma objetiva e constatável no comportamento dos trabalhadores e das equipes.

O clima organizacional por meio da administração, da forma de liderança, e da estrutura organizacional, contribui na modelagem do comportamento dos funcionários. Dessa maneira, pode haver um acréscimo na eficácia por intermédio de um clima que satisfaça a pretensão dos indivíduos e que direcione o comportamento gerado para consecução das atividades organizacionais (MCCLELLAND, 1972 apud GOMES, 2002).

REUNIR: Revista de Administração, Contabilidade e Sustentabilidade ISSN: 2237-3667, Vol. 5, n. 3, p.19-38, 2015 
Segundo Kolb et. al. (1978, apud Xavier, 1986) o comportamento é função dos interesses motivacionais e da percepção de clima organizacional do indivíduo. Sendo assim, Oliveira e Junior (2013) destacam que proporcionar um clima organizacional favorável é uma maneira de incentivar o comportamento positivo dos empregados.

O conhecimento do clima organizacional contribui com a identificação dos aspectos importantes para os funcionários, e, dessa forma, a organização pode estimular estes aspectos por meio da busca do comportamento organizacional positivo, isto é, as duas variáveis, clima organizacional e comportamento organizacional positivo, comportam-se como grandezas diretamente proporcionais.

\section{PROCEDIMENTOS METODOLÓGICOS}

Quanto aos fins, essa pesquisa pode ser classificada como explicativa, pois busca explicar a relação entre duas variáveis: clima organizacional e comportamento organizacional positivo. Quanto aos meios, esta pesquisa pode ser caracterizada como um estudo de caso.

Foi dividida em duas etapas, sendo a unidade de análise da primeira fase da pesquisa foi constituída por todos os 24 funcionários estatutários do setor de obras da Prefeitura de Tamboara-PR. Inicialmente o pesquisador utilizou a Escala de Clima Organizacional (ECO) apresentada por Martins (2008). Após a primeira fase foi utilizado um questionário semi-estruturado com questões abertas. A etapa 2 (dois) da pesquisa valeu-se de uma amostra de 12 funcionários, representando 50\% de uma população de 24 trabalhadores do setor de obras da prefeitura.

Para realizar a mensuração do clima organizacional foi utilizado a Escala de Clima Organizacional (ECO), explicada por Martins como (2008, p. 32) "[...] uma escala multidimensional construída e validada com o objetivo de avaliar a percepção do trabalhador sobre várias dimensões do clima organizacional". A escala é composta por 63 questões que apresentam escala likert, de 1 a 5 sendo: 1 para discordo totalmente; 2 para discordo; 3 para nem concordo nem discordo; 4 para concordo e 5 para concordo totalmente. As questões foram distribuídas em 5 elementos: controle/pressão, relacionamento entre colegas, conforto, suporte da organização e recompensa.

Primeiro calcula-se a média, depois soma-se a dos demais respondentes, quando realizado de forma individual, e divide pelo número de pesquisados, obtendo-se uma amplitude que varia entre 1 e 5. Após a obtenção das médias é realizada a interpretação do estado do clima, sendo que quanto maior for o valor da média, melhor é o clima organizacional da organização. Valores superiores a 4 
revelam um bom clima, enquanto valores menores que 2,9 indicam um clima ruim. $\mathrm{O}$ Fator controle/pressão é o inverso, a média maior indica um clima ruim (MARTINS, 2008). O resultado da ECO foi relacionado com as respostas dos entrevistados. A aplicação do questionário e a mensuração dos dados aconteceram no mês de junho de 2014.

\section{APRESENTAÇÃO E ANÁLISE DOS DADOS}

A Prefeitura Municipal de Tamboara, cidade localizada no noroeste do Paraná, é constituída como órgão público do poder executivo municipal. Essa instituição tem como atividade principal a prestação de serviços públicos aos munícipes. Segundo o IBGE (2014), Tamboara possui uma população estimada em quase 5 mil habitantes. Atualmente, a prefeitura possui em seu quadro efetivo de pessoal um total de 204 (duzentos e quatro) funcionários, destes 155 (cento e cinquenta e cinco) funcionários estatutários e 49 (quarenta e nove) funcionários nomeados e regidos pela CLT. O setor de obras, nosso objeto de estudo, conta com 24 funcionários estatutários.

Entre os 24 trabalhadores pesquisados 22 são do sexo masculino e 2 do sexo feminino. Em relação a faixa de idade um (4,2 \%) dos funcionários tem entre 31 e 36 anos, cinco (20,8\%) entre 37 e 43 anos e dezoito (75\%) possuem 44 anos ou mais, sendo a média de idade de 52 anos. Os cargos dos pesquisados são: um de pedreiro, três de operário, um de pintor, nove de vigilante de bens públicos, três de gari, um de motorista, um de auxiliar mecânico, um de servente de pedreiro, um de operador de pá carregadeira e um de servente de limpeza, estes funcionários possuem salários que variam de $\mathrm{R} \$ 724,00$ a $1.332,94$.

A seguir a Tabela 1, demonstra os resultados da ECO realizada com esses funcionários:

\begin{tabular}{|l|l|c|c|}
\hline \multicolumn{3}{|c|}{ Denominações, definições, itens integrantes e índices de precisão dos fatores da ECO } \\
\hline \multicolumn{1}{|c|}{ Denominações } & \multicolumn{1}{|c|}{ Definições } & \multicolumn{1}{|c|}{ Itens } & Média \\
\hline $\begin{array}{l}\text { Apoio da chefia e da } \\
\text { organização }\end{array}$ & $\begin{array}{l}\text { Suporte afetivo, estrutural e operacional da chefia e da } \\
\text { organização fornecido aos empregados no desempenho diário } \\
\text { de suas atividades no trabalho. }\end{array}$ & 1 ao 21 & 3,62 \\
\hline & $\begin{array}{l}\text { Diversas formas de recompensa usadas pela empresa para } \\
\text { premiar a qualidade, a produtividade, o esforço e o } \\
\text { desempenho do trabalhador. }\end{array}$ & 22 ao 34 & 3,69 \\
\hline Recompensa & $\begin{array}{l}\text { Ambiente físico, segurança e conforto proporcionados pela } \\
\text { empresa aos empregados. }\end{array}$ & 35 ao 47 & 3,61 \\
\hline & $\begin{array}{l}\text { Controle e pressão exercidos pela empresa e pelos } \\
\text { supervisores sobre o comportamento e desempenho dos } \\
\text { empregados. }\end{array}$ & 48 ao 56 & 3,72 \\
\hline Controle/pressão & União, vínculo e colaboração entre os colegas de trabalho. & 57 ao 63 & 3,56 \\
\hline Coesão entre colegas
\end{tabular}

Tabela 1. Denominações da ECO.

Fonte: Adaptado de Martins, (2008).

REUNIR: Revista de Administração, Contabilidade e Sustentabilidade

ISSN: 2237-3667, Vol. 5, n. 3, p.19-38, 2015 
A denominação "apoio da chefia e da organização", que conforme Martins (2008) é o apoio vindo dos que têm cargo superior na organização na consecução das tarefas diárias, teve uma média de 3,62. Esse valor é considerado mediano, já que de acordo com Martins (2008), médias acima de 4 geralmente apontam bom clima e abaixo de 2,9 mostram um clima ruim. Para Bispo (2006), um clima mediano pode gerar atitudes de indiferença e apatia nos funcionários o que não é atrativo para a organização.

Nessa primeira denominação (Itens 1 a 21), os itens que tiveram maior pontuação foram: "respeito do chefe com os funcionários", com média de 3,92, "aumento do desempenho por meio de novas ideias", com 3,92 e "aceite de mudanças propostas pelos funcionários" com 3,83. As menores médias nesse mesmo fator foram sobre o "conhecimento das informações que envolvem o setor" com 3,13, "a resolução de problemas no trabalho entre os funcionários" com 3,21, e com 3,33 o item "existência de orientação do chefe até o final nas tarefas que necessitam de maior tempo para consecução". De acordo com Santos et. al. (2009), o estilo gerencial é um fator que visa indicar o nível de satisfação que o empregado tem para com os seus superiores, avaliando a qualidade de direção por meio dos aspectos relacionamento, competência, feedback, capacidade de coordenação entre outros.

Quando perguntado aos entrevistados se o apoio dos chefes/superiores influencia em seu trabalho e por que, 58,33\%, confirmaram que há influência desse aspecto e justificaram:

E04 - Influencia, porque conseguindo o apoio dos supervisores o trabalho torna-se mais eficiente, devido a maior presença e às questões técnicas que apenas o supervisor pode resolver.

E12 - Influencia sim, pois é necessário que os chefes deem orientações e instruções para os indivíduos, com o intuito de ajudá-los a desempenhar as suas funções, além de que a própria figura dos superiores já é algo que passa mais segurança para os indivíduos.

E06 - Sim, porque pode auxiliar na execução de tarefas em que muitas vezes temos dúvidas ou dificuldades podendo tornar o trabalho mais gratificante.

8,33\% disse ser indiferente:

E07 - É indiferente, pois ser apoiado ou não, não afeta a qualidade e o desempenho de minhas funções.

$33,33 \%$ responderam negativamente:

E10 - Não, porque seu apoio não traz influência motivacional no meu trabalho, independente dele apoiar ou não, quem tem que ter vontade de realizar a ação é o próprio servidor.

E5 - Não influencia. Porque o trabalho que realizo não depende diretamente do apoio dos supervisores.

A denominação "recompensa", que de acordo com Martins (2008), pode utilizar várias formas para recompensar a produtividade e a qualidade da prestação

REUNIR: Revista de Administração, Contabilidade e Sustentabilidade ISSN: 2237-3667, Vol. 5, n. 3, p.19-38, 2015 
dos serviços, obteve uma média de 3,69, sendo a mais positiva entre os cinco fatores de análise da ECO. Bispo (2006) revela que a formação do elemento sentimento de recompensa ocorre por meio da sensação que o funcionário tem de retribuição a um trabalho feito de forma eficaz, da utilização de incentivos construtivos por parte da organização e da percepção do funcionário sobre o tratamento equitativo nos processos de promoção e gratificação. No fator "recompensa" (Itens 22 a 34) as maiores médias foram nos itens: "recompensa conforme o esperado pelo funcionário", "a eficaz execução das tarefas resultam em recompensa" e "funcionário sabe por qual motivo está recebendo recompensa", sendo essas médias, respectivamente de 3,92;3,83 e 3,79. As médias mais baixas estão nos itens: "os funcionários executam suas atividades com satisfação", com 3,29, "o salário está relacionado com a qualidade da consecução das tarefas", com 3,54, e com 3,63 de média ficaram os elementos "relação entre ganho e tarefas realizadas", e a "relação entre produtividade e salário".

Quando perguntado aos entrevistados se consideravam que o fator "recompensa" influenciava na consecução do seu trabalho e por que, 91,67\% confirmaram a influência desse aspecto:

E10 - Sim, quanto melhor for a remuneração do funcionário, maior será sua vontade na realização das atividades.

E06 - Sim, porque através da recompensa me sinto motivado a me empenhar cada vez mais em minha função.

E12 - Sem dúvida, o fator recompensa é um fator motivador, além de tudo não se pode considerar um local de trabalho que seja proveitoso sem pensar na remuneração por aquilo que se está fazendo.

E04 - Influencia, devido à sensação de estar ganhando o que é justo por seu serviço. Sensação essa que irá fazer com que o funcionário se empenhe mais na realização do trabalho.

8,33\% respondeu negativamente:

E11 - Não, este fator não influencia, porém traz mais ânimo mesmo que momentâneo, para melhor desempenhar as funções.

A remuneração é um dos itens que compõe o fator "recompensas". Conforme Santos et. al. (2009), quando analisado esse aspecto busca identificar se há distorções, internamente e externamente, na remuneração paga aos funcionários, verificando também se há descontentamento por parte dos empregados.

A denominação "conforto físico", que segundo Martins (2008), compreende aspectos como segurança e bem-estar do funcionário, apresentou a média de 3,61, valor considerado razoável. Conforme Santos et. al. (2010), esse aspecto visa saber o nível de satisfação dos empregados com as instalações físicas, conforto proporcionado e nível de segurança em situações de periculosidade e insalubridade. Em relação ao aspecto "conforto físico" (Itens 35 a 47) as maiores médias indicadas

REUNIR: Revista de Administração, Contabilidade e Sustentabilidade ISSN: 2237-3667, Vol. 5, n. 3, p.19-38, 2015 
pelos funcionários foram nos itens: "ambiente organizacional agradável", "ambiente de trabalho arejado" e "local de trabalho favorece o desempenho das atividades", com 3,79 de média em cada um dos itens. Esse fator teve as médias menores nos itens: "facilidade de movimentação para portadores de necessidades especiais", com 3,38, "existência de equipamentos de segurança", com 3,38, e "os equipamentos de segurança, são suficientes para não prejudicar a saúde do empregado" com 3,50.

Quando questionado aos entrevistados se a estrutura física influencia em seu trabalho e por que, todos os doze confirmaram que há influência desse aspecto:

E04 - Tem influência na qualidade dos trabalhos que serão entregues após a obra, porque uma empresa que possui uma estrutura permite maior gama de opções de ferramentas para o trabalhador, melhor ele lidará com problemas que surgirem durante a obra.

E05 - Influencia bastante, porque com uma boa estrutura, eu posso realizar meu trabalho sem correr o risco de faltar alguma peça ou algum equipamento.

A denominação "controle/pressão" diferencia-se dos demais, pois neste caso conforme Martins (2008, p.34), “[...] quanto maior o resultado, pior será o clima porque maior será o controle e a pressão exercidos sobre os empregados". A média dos nove itens desse fator ficou em 3,72, sendo então o ponto negativo de maior expressão dentre as cinco denominações elencadas na pesquisa. Segundo Bispo (2006), um clima organizacional mediano pode refletir na integração e na credibilidade da organização com os funcionários, o que pode acarretar em um comprometimento médio em relação à qualidade do serviço prestado por este. Esse autor destaca também, que nas organizações o excesso de regras, normas e procedimentos de conduta restringem o desenvolvimento da consecução das tarefas. O fator "pressão/controle" (Itens 48 a 56) na pesquisa teve como itens de maior média: "cobrança rígida em relação ao horário dos trabalhadores", com 3,83, "utilização das regras como forma do chefe repreender os funcionários", com 3,79, "cobrança para consecução das tarefas dentro do prazo determinado" e "prévia autorização do chefe para consecução de todas as tarefas", ambas com 3,75. Nesse quesito, as menores médias estão compreendidas nos itens: "fiscalização constante do superior", com média de 3,58, e "presença dos empregados é controlada de modo inflexível na organização", com 3,67.

Quando perguntado aos entrevistados se consideravam que o fator pressão da organização influenciava em seu trabalho e por que, $75 \%$ confirmaram que há influência desse aspecto:

E12 - Influencia tanto positiva quanto negativamente. Positivamente por que quando se está sob pressão adquire-se uma forma de pensar rápido, e negativamente pelo fato de que toda pressão é algo desgastante para os funcionários.

REUNIR: Revista de Administração, Contabilidade e Sustentabilidade ISSN: 2237-3667, Vol. 5, n. 3, p.19-38, 2015 
E07 - Só influencia de forma negativa, pois o rendimento sobre pressão tende a diminuir e se retrair.

E10 - Sim, só que negativamente, porque na minha opinião as pessoas não rendem sob pressão e ficam mais suscetíveis a cometer erros.

$25 \%$ confirmaram que não existe influência desse aspecto em seu trabalho:

E11 - Não, todos devemos nos acostumar com as cobranças dos superiores.

E04 - Não tem tanta influência porque todas as etapas são previamente programadas e devem ser seguidas sabendo que mudanças climáticas podem alterar essa programação estabelecida, não podendo haver, portanto, pressão sobre os funcionários e seus métodos de trabalho.

A denominação "coesão entre colegas", que para Martins (2008), refere-se ao vínculo formado nas relações interpessoais, obteve a média de 3,72, também considerada mediana pelo processo de avaliação de pesquisa da ECO. O relacionamento é citado por Bispo (2006) como a sensação que os indivíduos têm de cooperação, de ajuda recíproca que há no ambiente organizacional. Conforme Santos et. al. (2009) essa variável avalia o nível de relacionamento e a ajuda mútua entre os empregados e entre os setores. Nesse aspecto (itens 57 ao 63) obtiveram as maiores médias os itens: "integração com os funcionários da organização", com 3,92, "existe relação de amizade com os demais funcionários do setor", com 3,75, "quando o empregado erra é auxiliado pelos colegas", também com 3,75. Os itens que apresentaram as menores médias nesse fator foram: "confiança para compartilhar questões pessoais com alguns dos demais funcionários", com 2,63, "cooperação entre funcionários", com 3,50, e "funcionários atuais ajudam os novos funcionários", com 3,67 .

Quando questionado à amostra se o relacionamento com os demais colegas influencia em seu trabalho e por que, $75 \%$ confirmaram que há influência sim desse aspecto:

E12 - Sim, influencia pelo fato de que se não há um clima bom, um bom relacionamento com aqueles que trabalham juntos, acaba havendo um desânimo em trabalhar naquele local, o que é algo que pode prejudicar na produtividade dos funcionários.

E04 - Influencia no rendimento do serviço, porque a afinidade entre colegas de trabalho ajuda na cumplicidade e na ajuda mútua por uma finalidade em comum, que é a realização do trabalho.

Da amostra, 16,67\% disseram que a influência é relativa:

E07 - Depende do tipo de atividade, se houver contato com os colegas para a realização das tarefas influencia.

E02 - Às vezes, eu acho que no meu caso não influencia tanto, pois, por ser vigilante noturno tenho pouco contato com os demais servidores.

Sobre este aspecto 8,33\% afirmou não existir influência:

E11 - Não, é independente, a qualidade do trabalho não é influenciada pela amizade com os colegas.

REUNIR: Revista de Administração, Contabilidade e Sustentabilidade ISSN: 2237-3667, Vol. 5, n. 3, p.19-38, 2015 
A seguir são analisados os resultados que exercem maior influência positiva no desempenho do trabalho dos servidores de acordo com o apontado na ECO. Os itens referentes a esses resultados foram perguntados na entrevista.

O primeiro item é "respeito do chefe com os funcionários", 83,33\% dos entrevistados consideram esse item essencial, segundo esses funcionários:

E03 - Pois quando se tem o respeito do chefe com os funcionários, o relacionamento e o respeito mútuo tornam-se fatores-chave para $o$ desenvolvimento.

E04 - O respeito do chefe aumenta a confiança do empregado.

E02 - Respeito é essencial em qualquer ralação, tanto pessoal, amizade, trabalho, amorosa, pessoa respeitada rende mais.

Nesse sentido, é possível estabelecer uma relação com o comportamento organizacional positivo. Oliveira e Junior (2013) apontam que relações saudáveis entre gestores e subordinados, contribuem para um bom clima organizacional, e também são uma maneira de induzir o comportamento positivo dos funcionários, impactando em melhor desempenho das atividades. Além disso, McClelland (1972, apud Gomes, 2002) destaca que o clima organizacional é definido por meio da administração e da forma de liderança.

Em relação ao "aceite de mudanças propostas pelos funcionários", 25\% disseram ser um dos fatores de maior influência:

E07 - Todos têm que aceitar ideias e mudanças que contribuam de forma positiva.

E11 - Os chefes assim como os servidores devem aceitar as boas propostas.

$58,33 \%$ dos entrevistados acreditam que o quesito "recompensa conforme o esperado" é um fator influenciador importante:

E05 - A recompensa conforme o esperado faz com que o trabalhador sinta que seu trabalho foi valorizado.

E02 - A pessoa bem recompensada tem rendimento, mesmo que momentâneo, acima do anterior.

E07 - Todos esperam receber valores justos e nivelados com os funcionários que executam as mesmas tarefas ou similares.

Para 16,66\% dos entrevistados o fator "conhecimento do motivo pelo qual está sendo recompensado" é um dos que mais influencia positivamente o servidor:

E02 - É importante não somente ser recompensado, mas também saber o motivo de sua recompensa.

E11 - Quando houver recompensa o servidor deve saber pelo que está sendo recompensado.

Da amostra 33,33\% assinalaram que "a estrutura que a organização oferece para o desempenho das atividades" é um fator que influencia positivamente o comportamento do servidor, para os entrevistados:

E06 - A estrutura da organização é que determina uma plena execução das tarefas.

REUNIR: Revista de Administração, Contabilidade e Sustentabilidade

ISSN: 2237-3667, Vol. 5, n. 3, p.19-38, 2015 
E05 - Ela permite um trabalho sem imprevistos e um desempenho eficiente das atividades.

A estrutura organizacional, a forma que a instituição se organiza, é a principal influenciadora no clima organizacional segundo Tamayo (1999). Além disso, Bispo (2006) destaca a importância de mensurar o nível de influência que a estrutura tem sobre os funcionários e suas atividades.

Para 25\% dos pesquisados o fator "local de trabalho arejado" influencia de forma positiva o trabalho dos servidores, de acordo com os entrevistados:

E08 - Se o local de trabalho for agradável o trabalho será mais agradável sendo positivo para os funcionários.

E11 - Um local de trabalho limpo e seguro é essencial para uma boa prática do trabalho.

$41,67 \%$ afirmaram que o fator "relação de amizade com os demais colegas" resulta em uma influência positiva no desempenho do trabalho, conforme os entrevistados:

E10 - Isso melhora e é fundamental para um bom ambiente de trabalho, pois ajuda no desempenho das atividades.

E05 - A relação de amizade permite o trabalho em equipe e a integração de novas formas de trabalho.

Os gestores que usam de forma adequada o modelo de comportamento organizacional positivo ensinam seus empregados a construir um clima positivo que gere resultados benéficos para a organização e para os funcionários dedicados (NEWSTRON, 2008). Essa relação com o clima organizacional contribui para destacar a importância do COP para as organizações.

Com 8,33\% para cada item ficaram: "resolução de problemas vinda dos demais colegas" e "integração no trabalho com os demais colegas", segundo os servidores:

E06 - Quando todos estão integrados as funções são desenvolvidas da melhor maneira possível.

Os dados a seguir demonstram os três itens com maior influência negativa no desempenho do trabalho dos servidores, segundo a amostra pesquisada. Em relação ao fator "falta de conhecimento das informações que envolvem o setor de obras" $41,67 \%$ disseram que influencia negativamente no desempenho no trabalho:

E11 - Não saber questões relacionadas ao setor pode prejudicar as atividades.

E02 - Não saber o que se passa dentro do setor pode influenciar negativamente.

Em relação à última resposta, quando questionado o porquê dessa influência negativa o funcionário complementou:

E02 - No meu caso particular, existem pessoas, os motoristas do município, que se utilizam dos veículos à noite, se eu não souber disso, posso atrapalhar

REUNIR: Revista de Administração, Contabilidade e Sustentabilidade ISSN: 2237-3667, Vol. 5, n. 3, p.19-38, 2015 
outro funcionário que precisa utilizar o veículo e também as pessoas que necessitam deste transporte.

Sobre o quesito: "resolução de problemas entre os funcionários", 8,33\% afirmou ser um fator que influencia negativamente o desempenho funcional. Referente ao fator "orientação do chefe até o final das tarefas que demandam maior tempo para sua consecução", 8,33\% dos pesquisados acreditam que exerce má influência, conforme os entrevistados:

E01 - Com o chefe fiscalizando o serviço de maneira mais próxima, há influência negativa, pois dá a entender que o funcionário não possui capacidade para a realização da tarefa.

16,67\% afirmaram que o fator "salário" reflete em influência negativa:

E04 - O salário traz influência negativa, quando traz sensação de injustiça e quando o empregado não recebe o que é justo.

E09 - Um salário baixo desanima a fazer as tarefas.

Conforme $25 \%$ dos pesquisados o quesito: "ausência de preocupação com a saúde dos funcionários" é fator negativo, segundo eles:

E02 - Um superior que não se preocupa com o bem estar, a saúde do servidor, pode além de baixar o rendimento do setor, causar insatisfação.

E01 - Quando os chefes não se preocupam com o bem estar, saúde dos servidores, isso traz influência motivacional negativa, além de alavancar o índice de absenteísmo.

Para 25\% da amostra "a inexistência de equipamentos" é quesito negativo para o desempenho das atividades, de acordo com estes:

E02 - Todos nós, em regra, não gostamos e nem queremos correr riscos de vida e expor nossa saúde a situações adversas, equipamentos ideais e corretos quando não são disponibilizados pode gerar uma situação de insatisfação.

E10 - A execução de um serviço sem a existência de material adequado torna a prática trabalhista muito arriscada e de baixo rendimento.

Conforme Santos et. al. (2009), a averiguação desse quesito dá-se para a obtenção do conhecimento sobre a percepção dos empregados em relação a satisfação com o nível de segurança oferecido pela organização, fator influenciador do clima organizacional.

33,33\% afirmaram que "a utilização de regras como forma de repreender os funcionários" influencia negativamente no trabalho. Segundo os entrevistados essa é "uma maneira arcaica de administrar", um fator que deixa o clima organizacional pesado. Para 25\% o quesito "cobrança para a consecução das tarefas dentro do prazo" reflete negativamente na consecução das tarefas. Conforme os entrevistados, a cobrança pode gerar resultados desfavoráveis quando há dependência de variáveis que não estão ao controle do funcionário, podendo o excesso de cobrança gerar desconforto na consecução das atividades. 41,67\% afirmaram que "a necessidade de 
autorização do chefe para a consecução das tarefas" atrapalha no desempenho do trabalho. Para a amostra pesquisada, tarefas simples e corriqueiras não precisam ser autorizadas, sendo que a falta de flexibilidade e autonomia pode diminuir o desempenho da equipe. No fator "falta de cooperação entre os colegas de trabalho" houve uma das maiores porcentagens em relação à influência negativa gerada, $58,33 \%$, que corresponde a sete indivíduos. Para os entrevistados nem todos os colegas tem a mesma capacidade na execução das atividades, devendo haver, dessa forma, cooperação entre os funcionários. Como apontado por Newstron (2008) a empatia, que consiste na capacidade psicológica de se colocar no lugar do outro é estimulada pelo COP. Por essa razão, a falta de cooperação identificada influencia negativamente o clima organizacional e o COP da organização estudada.

Apesar da complexidade em estabelecer uma relação entre clima organizacional e o comportamento organizacional positivo, como apontam Espindola e Oliveira (2009), existe essa possibilidade. Oliveira e Junior (2013) destacam que a manutenção de um bom clima pode ser conseguida buscando-se o comportamento organizacional positivo dos empregados, de modo que esses sejam levados a satisfazer suas necessidades e desejos, o que provavelmente incorrerá em um bom desempenho das tarefas por parte destes.

\section{CONSIDERAÇÕES FINAIS}

O objetivo deste trabalho foi analisar como a percepção sobre o clima organizacional dos servidores do setor de obras da prefeitura de Tamboara-PR influencia em seu comportamento organizacional positivo. Certificou-se, conforme apresentado no confronto da teoria com a pesquisa de campo, que clima e comportamento organizacional positivo são elementos indissociáveis, pois um bom clima organizacional induz o COP. Dessa forma as variáveis que afetam o primeiro consequentemente afetarão o segundo. Verificou-se também que dentro de uma organização o fator financeiro não é o único que reflete no comportamento e no desempenho das tarefas, questões como relação interpessoal, reconhecimento por um bom trabalho prestado e estrutura organizacional que favoreça a consecução das tarefas também são quesitos que exercem sua parcela de influência.

Constatou-se também que o fator recompensa realiza grande influência positiva no desempenho do trabalho. Como fator negativo a falta de cooperação entre os colegas de trabalho foi o que obteve maior percentual, o que acaba demonstrando a importância da empatia, uma das capacidades promovidas pelo COP e por um clima organizacional favorável. 
É perceptível que clima organizacional e comportamento organizacional positivo são fatores que se influenciam mutuamente, e, por meio da pesquisa de clima organizacional a organização tem conhecimento de quais aspectos influenciam seus funcionários, o que pode ser utilizado para proporcionar aos empregados um ambiente mais benéfico gerando os benefícios do comportamento organizacional positivo como a empatia entre os colegas.

Por fim, pode-se concluir que as organizações que proporcionam um clima organizacional que favoreça os funcionários tendem a possuir equipes mais satisfeitas e produtivas. Esse resultado contribui com todas as organizações, em especial, as do setor público, que como a estudada neste trabalho, buscam equilibrar seus gastos, aumentando a eficiência de suas ações.

\section{REFERÊNCIAS}

ANDRADE, S. M. de.; FISCHER, A. L.; STEFANO, S. R. Confiança Organizacional e Interpessoal como uma Dimensão de Clima Organizacional: Um estudo a partir da percepção dos empregados das organizações que pretendem se destacar pela qualidade do ambiente de trabalho. III Encontro de GP e Relações de Trabalho, João Pessoa-PB, 2011.

BISPO, F. C. A. Um novo modelo de pesquisa de clima organizacional. v. 16, n. 2, p. 258-273, Maio/Ago, 2006.

BOHLANDER, G.; SNELL, S.; SHERMAN, A. Administração de Recursos Humanos. São Paulo: Cengage Learning, 2009.

CHIUZI, R. M.; SIQUEIRA, M. M. M.; MARTINS, M. C. F. As dimensões da organização positiva e seus impactos sobre o bem-estar dos trabalhadores. Psicologia da Saúde, 20 (1-2) 31-40, Jan-Dez, 2012.

CUNHA, M. P.; REGO, A; LOPES, M. P. Comportamento Organizacional Positivo. Análise Psicológica. Lisboa, v.4 (XXXI), p. 313-328. 2013.

EBOLI, Marisa. As pessoas na organização. 7. Ed. São Paulo: Editora Gente, 2002.

ESPINDOLA, M. B.; OLIVEIRA, A. P. V. D. Análise comportamental: um estudo de como o comportamento organizacional pode influenciar o clima organizacional de uma indústria. Revista digital FAPAM, Pará de Minas, v.1, n.1, 179-200, Out. 2009. 
GIL, A. C. Como elaborar projetos de pesquisa. 4. ed. São Paulo: Atlas, 2002.

GOMES, F. R.. Clima Organizacional: um estudo em uma empresa de telecomunicações. RAE - Revista de Adm. de Empresas. São Paulo, v. 42, n. 2, p. 95103. Abr/Jun. 2002.

KNAPIK, J. Gestão de Pessoas e talentos. 2. ed. Curitiba: Ibpex, 2008.

KOLB, D. A.; RUBIN, I. M.; McINTYRE, J. M. Psicologia organizacional: uma abordagem vivencial. São Paulo: Atlas, 1978.

LUTHANS, F. The need and meaning of positive organizational behavior. Journal of Organizacional Behavior. p. 695. Set. 2002.

MARTINS, M.C.F. Comportamento Organizacional: Ferramentas de diagnóstico e gestão. Porto Alegre: Artmed, 2008.

MCSHANE, S. L.; GLINOW, M. A. V. Comportamento organizacional: conhecimento emergente, realidade global. São Paulo: McGraw Hill, 2014.

NEWSTROM, J. W. Comportamento organizacional: o comportamento humano no trabalho. ed. 12. São Paulo: McGraw Hill, 2008.

OLIVEIRA, L. C. C.; JUNIOR, A. B. F. As atitudes dos colaboradores em relação aos gestores culturalmente diferenciados. Organização Sistêmica. Vol. 2, n. 2. Jan/Jun 2013.

PAYNE, R. L.; MANSFIELD, R. Relationships of perceptions of organizational climate to organizational structure, context, and hierarchical position. Administrative Science Quarterly, 1973.

PALMA, P. J. ; CUNHA, M. P.; LOPES, M. P. Comportamento organizacional positivo e empreendedorismo: uma influência mutuamente vantajosa. Comportamento organizacional e gestão, vol. 13, n. ${ }^{\circ}$ 1, 93-114, 2007. 
PUENTE-PALACIOS, K. E.. Abordagens teóricas e dimensões empíricas do conceito de clima organizacional. Revista de administração, São Paulo v.37, p.96104, julho/setembro 2002.

SANTOS, G. J.; MACÊDO, M. N. M.; GADELHA, A. M.; RAMALHO, C. Â. M.; SILVA, F. S. Clima organizacional: um estudo de caso em uma empresa varejista em Campina Grande - PB. VII Simpósio de Excelência em Gestão em Tecnologia. Campina Grande - Paraíba, 2010.

SBRAGIA, R. Um estudo empírico sobre clima organizacional em instituições de pesquisa. Revista de Administração, v. 18, n. 2, p. 30-39, 1983.

SEligman, M. E. P.; CSIKSZENTMIHALYI, M.. Positive Psychology. American Psychologist Association, vol. 55. n. 1, p. 5-14, 2000.

SIQUEIRA, M. M. M.. Novas medidas do comportamento organizacional: Ferramentas de diagnóstico e de Gestão. Porto Alegre: Artmed, 2014.

SOUZA, A. C. de; FILHO, F.; OTANI, N. TCC: métodos e técnicas. Florianópolis: Visual Books, 2007.

TAMAYO, A. Valores e clima organizacional. In: PAZ, M. G. T.; TAMAYO, A. (Orgs). Escola, saúde mental e trabalho.Brasília: Editora UnB, 1999.

VELOSO, E. F. R. NAKATA, L. E. FISCHER, A. L., DUTRA, J. S. Pesquisas de clima organizacional: o uso de categorias na construção metodológica e análise de resultados. XXXI Encontro da ANPAD, Anais eletrônicos, Rio de janeiro, 22 a 26 de Janeiro de 2007.

XAVIER, O. S. Clima Organizacional na pesquisa agropecuária: percepção e aspiração. Revista de Administração, vol. 21(4), Pág. 33-48. Out/Dez, 1986. 